\title{
Cortisone Acetate
}

National Cancer Institute

\section{Source}

National Cancer Institute. Cortisone Acetate. NCI Thesaurus. Code C1058.

The acetate salt form of cortisone, a synthetic or semisynthetic analog of the naturally occurring cortisone hormone produced by the adrenal glands with anti-inflammatory and immunomodulating properties. Cortisone acetate diffuses through the cell membrane and binds to nuclear glucocorticoid receptors. The receptor-lig and complex binds to promotor regions of certain genes and initiates RNA transcription. This results in an induction of synthesis of certain anti-inflammatory proteins while inhibiting the synthesis of certain inflammatory mediators. 